\title{
UVODNIK
}

\section{SODOBNI VOJAŠKI IZZIVI V ANGLEŠKEM JEZIKU - PROBLEM ALI PRILOŽNOST}

Spoštovani bralke in bralci!

Pred vami je nova številka Sodobnih vojaških izzivov, v kateri smo objavili nekaj tem, ki so jih napisali avtorji, zaposleni v slovenskem obrambnem sistemu, vsi, razen enega, so iz Slovenske vojske. Tako nadaljujemo tradicijo, da je zadnja številka v letu namenjena domačim vojaškim piscem.

Prejšnja tematska številka, posvečena hibridnim grožnjam, ki je izšla v celoti v angleškem jeziku, je zaradi angleškega jezika pri bralcih vzbudila različne odzive, čeprav smo nekatere članke objavili v elektronski različici na naših spletnih straneh tudi v slovenskem jeziku. Prejeli smo pismo bralca, ki je posebej izpostavil problematiko izhajanja slovenske publikacije v angleškem jeziku in se hkrati strinjal, da njegovo pismo objavimo na spletnih straneh Sodobnih vojaških izzivov, v rubriki Polemike, odgovori, komentarji, na katerih je objavljen tudi naš odgovor.

Bralec je izpostavil predvsem skrb za ohranjanje in razvoj slovenskega vojaškega jezika, posredno pa nanizal nekaj pomislekov, zaradi katerih menimo, da je tudi tukaj treba dati nekaj pojasnil, povezanih z izhajanjem Sodobnih vojaških izzivov.

Slovenska vojska v okviru razvijanja vojaške strokovne literature, kar ji nalaga Zakon o obrambi, izdaja več različnih periodičnih publikacij, kot na primer Vojaškošolski zbornik, Vojaško zgodovino in druge publikacije, ki izhajajo priložnostno (Prava smer, Prvi, Modri ipd.). Ministrstvo za obrambo izdaja tudi štirinajstdnevnik Slovenska vojska.

Med vsemi publikacijami, ki jih izdaja Slovenska vojska, so Sodobni vojaški izzivi edina, ki je na kakovostni ravni znanstveno-strokovne publikacije in je uvrščena na seznam revij Javne agencije RS za raziskovalno dejavnost. Eden izmed kakovostnih 
pogojev je, da je ena izmed štirih številk, ki izidejo na leto, v angleškem jeziku. Objava v njej prinaša točke $v$ habilitacijskem postopku, in sicer skladno z zakonodajo, ki ureja področje visokega šolstva. Tako je objava članka v publikaciji motiv tako za zunanje strokovnjake in znanstvenike kot za zaposlene v obrambnem sistemu.

O pomenu razvoja kakovostnih slovenskih vojaških znanstveno-strokovnih vsebin so v več člankih pisali mnogi domači avtorji ${ }^{1}$, med mlajšimi generacijami pa z uredniškim odborom sodelujejo številni strokovnjaki in znanstveniki z različnih fakultet in drugih ustanov. Od uvrstitve publikacije v mednarodno podatkovno bazo se je povečalo zanimanje tujih in domačih avtorjev za objavo v njej. Ne nazadnje se v obrambnem sistemu število kakovostnih piscev povečuje, kar dokazujejo članki in statistika, objavljena na spletnih straneh.

Uredniški odbor ima stike in sodeluje z različnimi poveljniško-štabnimi šolami v državah članicah EU in zavezništva, z njimi izmenjuje izkušnje, pridobljeno znanje in nova spoznanja. Želimo si, da bi v publikaciji Slovenske vojske lahko objavili svoje članke tudi drugi vojaški strokovnjaki in znanstveniki, predvsem pa, da bi naše znanje in izkušnje lahko spoznali tudi drugi iz partnerskih držav.

Dodano vrednost nedvomno pomenita izmenjava s tujimi vojaškimi znanstveno-strokovnimi publikacijami in sodelovanje med uredniškimi odbori ${ }^{2}$. Sodelujemo tudi z ustanovami, kot so Center za civilno-vojaške odnose iz Montereya v ZDA, Center za varnostne študije George C. Marshall iz Nemčije, Raziskovalni institut za Evropske in ameriške študije iz Grčije in drugi.

Pri nastajanju slovenske vojaške literature sodelujejo različni strokovnjaki, med drugim tudi lektorji in prevajalci. Rezultati sodelovanja obeh strok so tako privedli do izida nekaterih slovenskih terminoloških priročnikov in slovarjev ${ }^{3}$. S povsem čisto vestjo lahko zapišemo, da se tako na Ministrstvu za obrambo kot v Slovenski vojski trudimo po najboljših močeh za kakovostno razvijanje slovenske vojaške literature in terminologije, je pa res, da nas na tem področju čaka še veliko dela.

Navedenega seveda ne razumemo kot razlog za počitek na lovorikah. Mednarodno varnostno okolje je zelo dinamično in Slovenska vojska je del tega okolja. Vsakdanjik v njej pomeni nenehen izziv in potrebo po dokazovanju kakovosti.

\footnotetext{
Npr.: Kranjc, Marijan F., Slovenska vojaška inteligenca. Grafis Trade. Grosuplje, 2005; Žabkar, Anton, Marsova dediščina, temelji vojaških ved, 1. knjiga. Fakulteta za družbene vede, Ljubljana, 2003; Žabkar, Anton, Marsova dediščina, metode in smeri razvoja, 2. knjiga. Fakulteta za družbene vede, Ljubljana 2004; Žabkar, Anton, Svete, Uroš, Šolanje vojaških profesionalcev med tradicionalnimi izhodišči in (post)modernimi izzivi. Bilten Slovenske vojske, 10/ št. 1 (maj 2008), str. 183-208. Generalštab Slovenske vojske, Ljubljana, 2008.

2 Npr:: Parameters in Military \& Society iz ZDA, Romanian Military Thinking iz Romunije, Vojnotehnički glasnik iz Srbije, Boletim, Proelium in Revista de Ciências Sociais e Politicas iz Portugalske.

3 Npr.: Slovar inženirskih izrazov, Slovensko-nemški vojaški slovar, Jezikovni priročnik za tolmače in prevajalce, Razlagalni vojaški slovar (2009, prvi del).
} 
Osebno sem prepričana, da slovenščina kot jezik z dolgoletno tradicijo v Slovenski vojski ni ogrožena. Menim, da sta članstvo in vloga naše države v mednarodnih integracijah danes precej drugačna, kot sta bila v nekdanji skupni državi. Lektorjem in prevajalcem, ki podpirajo nastajanje Sodobnih vojaških izzivov že trinajsto leto, je razvijanje njihove stroke vsakdanji izziv in ne problem, za publicistiko in razvijanje slovenske vojaške znanstveno-strokovne literature in izmenjavo znanja $\mathrm{z}$ drugimi pa velika priložnost.

Mnenja bralk in bralcev so dragocen motiv za razmislek, ali so naši cilji pravi in katera pot za dosego teh ciljev je najboljša. Na naše odločitve poleg drugih dejavnikov v zadnjem obdobju veliko vplivajo tudi finančni vidiki izdajanja publikacije.

K sodelovanju pri vsebinskem nastajanju Sodobnih vojaških izzivov tako kot vedno vabimo vse, ki bi želeli prispevati k razvoju vojaških vsebin. Polemike in komentarji so seveda dobrodošli, pa vendar so strokovni in znanstveni članki, napisani skladno z Navodili avtorjem za oblikovanje prispevkov, ki so objavljena na koncu publikacije, tista »boljša pot« za razvoj kakovosti vojaške literature.

V tokratni številki Sodobnih vojaških izzivov Tanja Pečnik predstavlja temo z naslovom Geopolitična determiniranost Slovenske vojske - oblikovanje večnacionalnih sil na območju Zahodnega Balkana, v kateri je želela preveriti možnost, ali Slovenija ali katera izmed drugih nekdanjih republik Jugoslavije razmišlja o širitvi svojega geopolitičnega vpliva tudi prek tesnejših vojaških povezav.

Celovitemu načrtovanju operacij v Natu se je posvetil Jože Grozde, ki pravi, da se je reševanje kriznih razmer le z vojaško silo v konfliktih po hladni vojni izkazalo kot neučinkovito, saj ni zagotovilo bistvenega izboljšanja varnostnih razmer. Nato uvaja celovito načrtovanje operacij, ki podpira celovit pristop mednarodne skupnosti $\mathrm{k}$ reševanju kompleksnih kriz.

Vojko Obrulj v Paradigmi vodenja in poveljevanja pri uvajanju vojaške discipli$n e$ vojaško disciplino obravnava $\mathrm{z}$ dveh vidikov, in sicer kot odnos posameznika do vojaške discipline in kot disciplino vedenja.

Pravila oziroma kodeks ravnanja in vedenja za izvajalce izobraževanja in usposabljanja $v$ Slovenski vojski je tema, ki je k pisanju spodbudila Mojco Pešec. Izvajalci izobraževanja in usposabljanja so zavezani k doseganju najvišjih standardov usposobljenosti in tudi k spoštovanju vrednot, ki uravnavajo medsebojne odnose udeležencev, zato predlaga sprejetje takega dokumenta.

Branko Podbrežnik nam v članku z naslovom Pogledi pripadnikov SV na napotitve na mednarodne dolžnosti $v$ tujino predstavlja rezultate raziskave, ki jo je opravil med temi pripadniki. Ugotavlja, da se ti spopadajo z različnimi izzivi, ki se dotikajo tako njih osebno, njihovega življenja in dela kot tudi življenja celotne družine in kako jih pri tem podpira obrambni sistem. 
Izzivi strategije razvoja storitev informacijskih in komunikacijskih tehnologij v obrambnih sistemih in oboroženih silah so spodbudili k pisanju Mihaela Naglja. Ugotavlja, da izkušnje uresničevanja poslovnih strategij modernih organizacij kažejo, da je strategije mogoče uresničevati le z izkoriščanjem naprednih informacijskih tehnologij.

Želimo vam zanimivo branje, morda se vam ob teh vsebinah utrne zamisel za katero izmed novih ali že znanih vsebin, ki bi jo lahko na novo ali drugače predstavili drugim. 